\title{
Grain Refinement of Commercial Purity Magnesium Processed by ECAP (Equal Channel Angular Pressing)
}

\author{
Flávia Spitale Jacques Poggialia*, Roberto Braga Figueiredo ${ }^{\mathrm{b}}$, \\ Maria Teresa Paulino Aguilar ${ }^{\mathrm{b}}$, Paulo Roberto Cetlin ${ }^{\mathrm{c}}$ \\ ${ }^{\mathrm{a}}$ Department of Metallurgical and Materials Engineering, Federal University of Minas Gerais, - UFMG, \\ Belo Horizonte, CEP 31270-901, MG, Brazil \\ ${ }^{\mathrm{b}}$ Department of Materials Engineering and Construction, Federal University of Minas Gerais, - UFMG, \\ Belo Horizonte, CEP 31270-901, MG, Brazil \\ 'Department of Mechanical Engineering, Federal University of Minas Gerais, - UFMG, \\ Belo Horizonte, CEP 31270-901, MG, Brazil
}

Received: September 30, 2011; Revised: January 15, 2012

\begin{abstract}
Grain refinement in magnesium is evaluated in the present paper. Equal Channel Angular Pressing is used to process commercially pure magnesium. Processing was carried out at $523 \mathrm{~K}$ which is lower than the temperature used in other papers on the literature. The grain structure was evaluated throughout the deformation zone. The low processing temperature prevents significant grain growth. The evolution of the grain structure is compared to a recent model for mechanism of grain refinement in magnesium. The present results confirm the validity of the model.
\end{abstract}

Keywords: magnesium, severe plastic deformation (SPD), ECAP

\section{Introduction}

\subsection{Equal Channel Angular Pressing (ECAP)}

Severe plastic deformation-SPD techniques have been widely used to refine the grain structure and improve mechanical properties of metallic materials. These techniques differ from conventional forming operations because plastic deformation is introduced without changes in the cross-section of samples. Therefore processing can be repeated indefinitely leading to large amounts of imposed deformation and exceptional structure refinement ${ }^{1}$.

Equal-channel angular pressing-ECAP is the most common SPD technique. This process is characterized by the pressing of a well-lubricated billet through a die in which two channels, with similar cross-section, intercept at an abrupt angle. The billet cross-section is not altered after being processed by ECAP and the process can be repeated multiple times ${ }^{2}$. The amount of plastic deformation per pass of ECAP depends on the angle between the channels and the external curvature in the intersection between channels ${ }^{3}$ but it is $\sim 1$ for the most common dies which have $90^{\circ}$ between channels. Figure 1 shows an illustration of a typical die of ECAP. The geometry of the die is characterized by the angle between channels, $\Phi$, and the angle of curvature at the intersection between channels, $\Psi$.

There is a growing interest in the use of ECAP to process magnesium and its alloys, as early papers reported significant grain refinement and improvement in mechanical properties of these materials. Magnesium is a low density $\left(\sim 1,7 \mathrm{~g} \cdot \mathrm{cm}^{-3}\right)$ metallic material with exceptional strength

*e-mail: spitale@ufmg.br to weight ratio. Therefore there is a great interest in the transportation industry in developing processing techniques to increase its use. Other metallic materials widely used in the transportation industry such as aluminum $\left(\sim 2,7 \mathrm{~g} . \mathrm{cm}^{-3}\right)$ and titanium $\left(\sim 4,5 \mathrm{~g} . \mathrm{cm}^{-3}\right)$ exhibit higher density.

Magnesium has low formability at low temperatures due to the limited number of slip-systems in its h.c.p. structure. Therefore ECAP processing is usually carried out at high temperatures, typically $\sim 473-673 \mathrm{~K}$. This temperature range is larger than half the melting temperature of magnesium $(\sim 923 \mathrm{~K})$ and leads to structure refinement by recrystallization. However, the mechanism of grain refinement in these materials is not clear yet.

Experiments in a Mg-3\% Al-1\% Zn alloy revealed a gradual and homogeneous decrease in the average grain size in successive passes of $\mathrm{ECAP}^{4}$. The researchers proposed a mechanism of grain refinement in which multiple nuclei of recrystallized grains are formed homogeneously throughout the volume of the processed material and grow until the grain boundaries intercept each other. This mechanism predicts the formation of equiaxed grains with a narrow size distribution.

Early papers ${ }^{5,6}$ reported that recrystallization in magnesium alloys deformed in the temperature range of $\sim 423-673 \mathrm{~K}$ occurs by the nucleation of grains along grain boundaries of former grains. This leads to a necklace pattern in the grain structure and multi-modal distribution of grain sizes. Many papers have reported multi-modal distribution of grain sizes in magnesium alloys processed by few passes of ECAP. A new model of grain refinement was proposed 


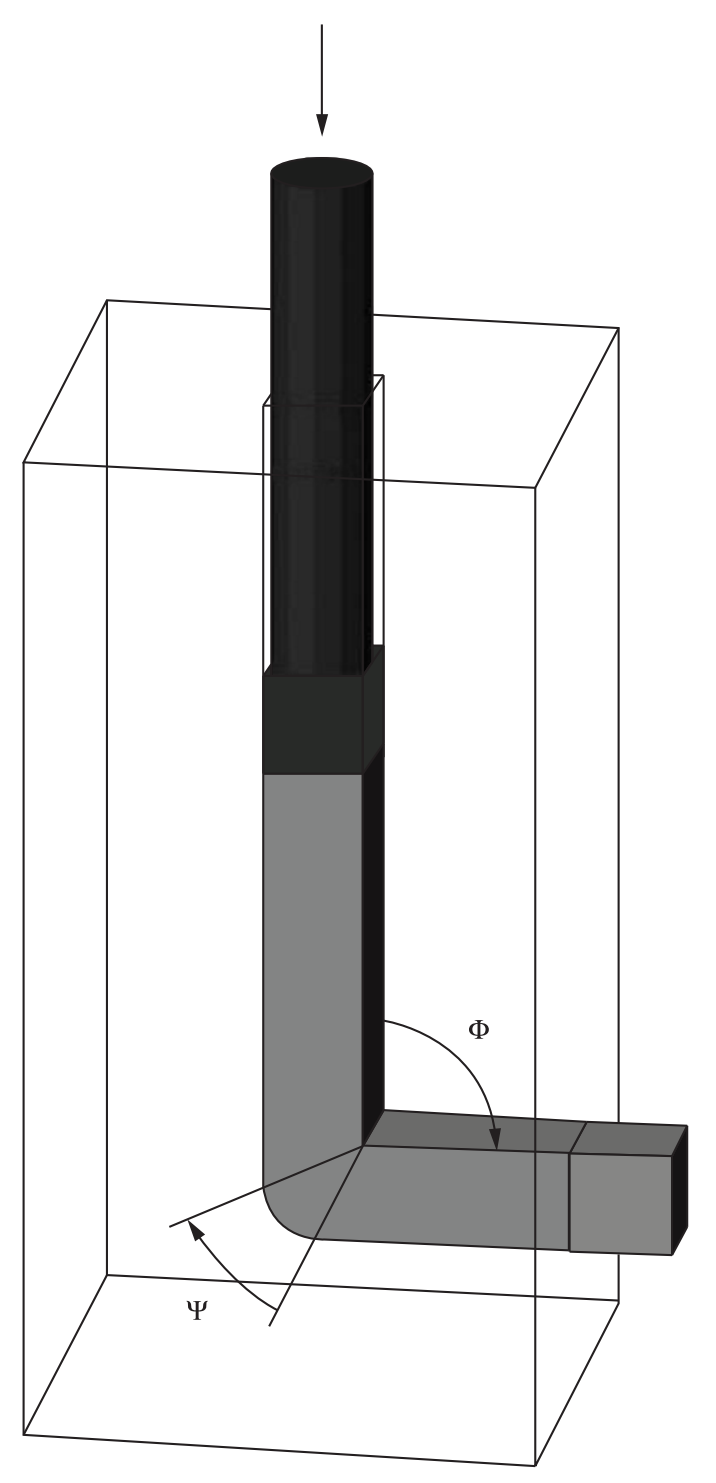

Figure 1. Illustration of an ECAP die.

recently ${ }^{7}$ taking into account these observations. This model agrees with experimental observation of the grain structures in many magnesium alloys processed by different number of passes of ECAP. However, some papers ${ }^{8,9}$ reported nearly homogeneous grain distribution on coarse grained pure magnesium processed by ECAP which does not agree with the model. These observations were made after a complete pass of ECAP and grain growth might have taken place as the billet is held at high temperature at the exit channel. On the other hand, some papers ${ }^{10,11}$ report heterogeneous grain size distribution on pure magnesium when processed at lower temperatures. A detailed observation of the structure evolution throughout the deformation zone is still missing.

The present paper reports the grain structure evolution of commercial purity magnesium within the deformation zone of ECAP. The mechanism of nucleation of recrystallized grains is evaluated.

\section{Experimental Material and Procedures}

The material used in the present investigation was a commercial-purity magnesium. The material was received in the as-cast state. The analysis of the initial material reviewed a coarse grain structure with average grain size larger than $1 \mathrm{~mm}$. Cylindrical billets with $9.8 \mathrm{~mm}$ diameter and $60 \mathrm{~mm}$ length were machined from the as-received material.

The billets were processed by ECAP using a die with $90^{\circ}$ between channels and $45^{\circ}$ of external curvature. ECAP was carried out at $\sim 523 \mathrm{~K}$ with a plunger speed of $0.1 \mathrm{~mm} / \mathrm{s}$. A lubricant based on $\mathrm{MoS}_{2}$ was used between the billets and the die in order to reduce friction. This lubricant is indicated for use up to $723 \mathrm{~K}$. Load and displacement data were collected during pressing up to a displacement of $\sim 40 \mathrm{~mm}$. The billet and the die were air-cooled for $\sim 30$ minutes. and the billet was removed from the die in order to preserve the deformation zone structure.

A sample was cut from the billet, around the deformation zone, with the surface parallel to the longtitudinal plane. The sample was cold mounted in resin, ground with silicon carbide papers (\#180, \#400, \#600 and \#1000) and polished in cloth with diamond paste $(9,3$ e $1 \mu \mathrm{m})$ to a mirror-like finishing. The polished surface was etched with a solution of $5 \%$ vol. nitric acid and $95 \%$ vol. ethanol and observed on an optical microscope.

\section{Experimental Results}

\subsection{ECAP processing}

Figure 2 shows the load as a function of the stroke during ECAP processing of magnesium. Reduced load is observed in the initial stage of processing $(<5 \mathrm{~mm})$ which is attributed to bending of the edge of the billet in the area of intersection between the channels in the die. A pronounced increase in load is observed between $\sim 5$ and $\sim 10 \mathrm{~mm}$ which is attributed to the filling of the volume in the intersection between the channels by the billet. The steady-state processing by ECAP begins at a load of $\sim 10 \mathrm{kN}$ corresponding to a pressure of $\sim 130 \mathrm{MPa}$. An increase in load is observed throughout steady-state ECAP processing suggesting an increase in friction.

Figure 3 shows images of the billet after being partially processed by ECAP. The image on the left side shows the appearance of the surface on the inlet channel. There are marks of removed material on the surface of the billet which confirms that friction was high. The image on the right side shows the appearance of the billet in the region of the intersection between the channels in the die. It is observed that processing took place without visible cracks on the surface of the billet.

\subsection{Evolution of grain structure in the deformation zone}

Figures 4-6 show the evolution of the grain structure at different locations of the deformation zone. Figure 4 shows the appearance of the structure entering the deformation zone. The coarse grain structure of the as-received material is still present but pronounced twinning already took place. Serrations are observed along the grain boundaries. 


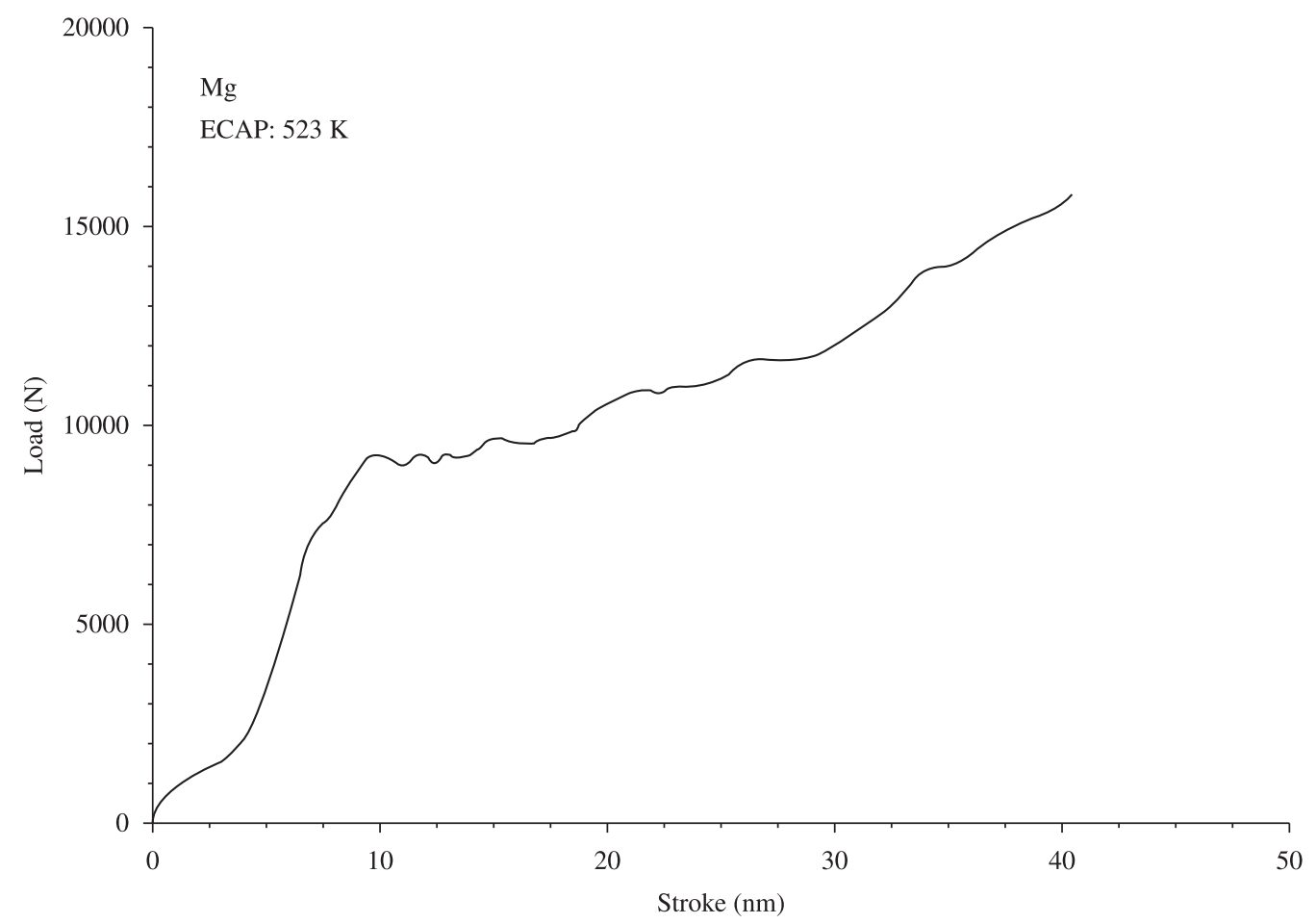

Figure 2. Load versus. stroke curve for ECAP processing of magnesium.
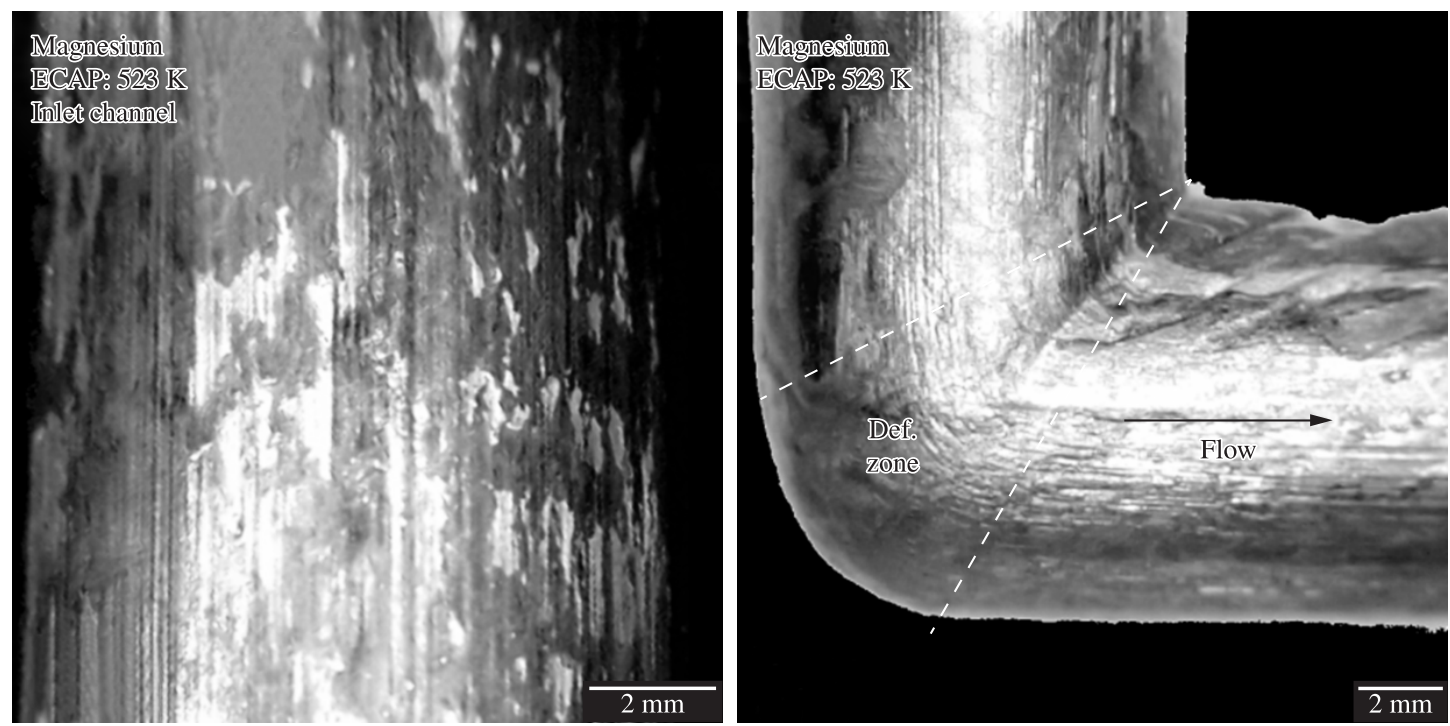

Figure 3. Appearance of the surface of the billet of magnesium in the inlet channel (left) of the ECAP die and in the region of the intersection between the channels (right). The deformation zone and the direction of flow are indicated.

Figure 5 shows the grain structure in a region inside the deformation zone. Fine grains $(\sim 20 \mu \mathrm{m})$ are observed inside twins and around grain boundaries of the original coarse grained structure. Fine grains are not observed far from the original grain boundaries or from the twins.

Figure 6 shows the grain structure at the end of the deformation zone. It is observed that fine grains occupy a large fraction of the area. The average size of the fine grains $(\sim 15 \mu \mathrm{m})$ is similar to the average size of the fine grains in the deformation zone. The fine grains are distributed in a necklace pattern around areas of unrefined coarse grains $(>100 \mu \mathrm{m})$. The average grain size of the whole structure is $\sim 25 \mu \mathrm{m}$.

\section{Discussion}

The present results confirm that it is possible to process as-cast pure magnesium by ECAP at $523 \mathrm{~K}$ without 


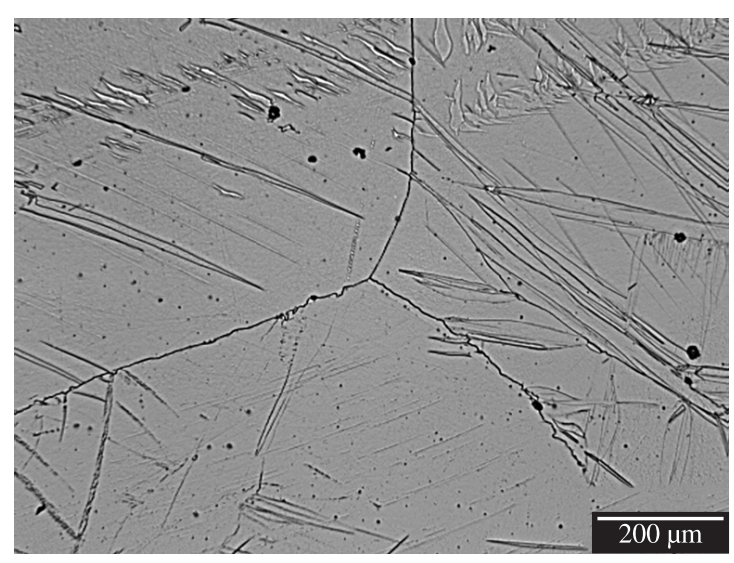

Figure 4. Grain structure at the beginning of the deformation zone.

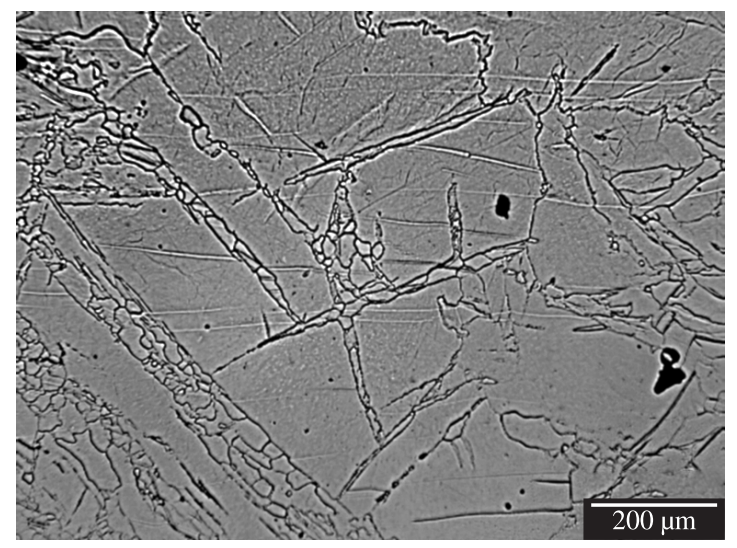

Figure 5. Grain structure inside the deformation zone.

cracks. This temperature is similar to the reported in a recent publication ${ }^{10}$. Earlier papers ${ }^{8,9}$ reported a minimum temperature of $623 \mathrm{~K}$ to successfully process pure magnesium without cracks.

The grain structure evolution observed in the present investigation is in agreement with a model proposed recently ${ }^{7}$. Fine grains nucleate around original grain boundaries and inside twins but unrefined areas are still observed away from the boundaries leading to a bimodal grain structure. An earlier paper ${ }^{4}$ proposed a mechanism at which recrystallized grains nucleate throughout the original grains and grow until an homogeneous equiaxed structure.

The difference between the models for grain refinement lie on the nucleation sites for the new grains and the possibility of developing a heterogeneous grain size distribution. Some papers reported heterogeneous grain size distribution on magnesium alloys. However, some

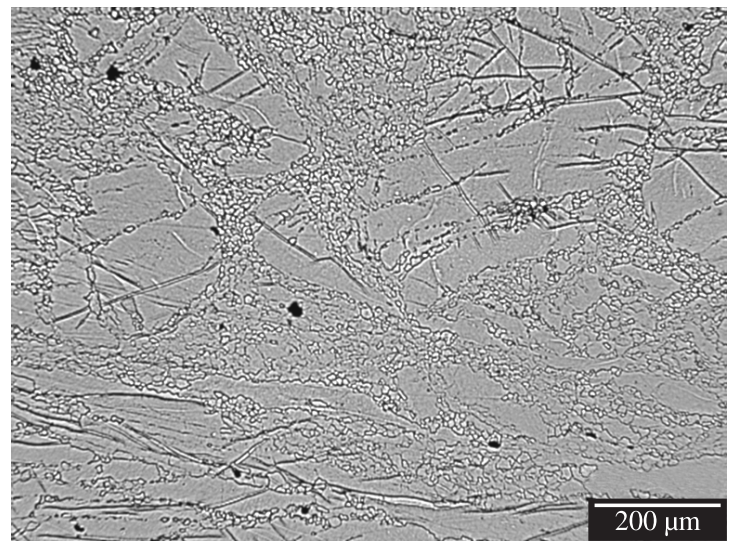

Figure 6. Grain structure at the end of the deformation zone.

papers reported nearly homogeneous grain size distribution in pure magnesium processed by ECAP at $673 \mathrm{~K}^{[8]}$ and $623 \mathrm{~K}^{[9]}$. These nearly homogeneous distribution of grain sizes disagree with the prediction from the model of grain refinement proposed elsewhere ${ }^{7}$ because the initial grain sizes were too coarse. However the grain structure was observed after a complete pass of ECAP and grain growth might have taken place in the workpieces. The present results show the grain structure at different stages of deformation. It is shown that fine grains nucleate at grain boundaries and at twin boundaries as predicted by the grain refinement model leading to heterogeneous grain size distribution. The intermediate processing temperature $(523 \mathrm{~K})$ prevented grain growth and a bimodal grain size distribution was still observed after a complete pass of ECAP. Therefore the grain size evolution in pure magnesium processed by ECAP also follow the trend predicted in a recent paper ${ }^{7}$.

\section{Conclusions}

Commercial purity magnesium was successfully processed by one pass of ECAP at $523 \mathrm{~K}$. The pressing was stopped during steady-state processing and the grain structure was evaluated. The following conclusions are drawn:

1) Twinning and grain boundary serrations occur in the early stage of deformation and fine grains nucleate around original grain boundaries and inside twins in the next stage;

2) A bi-modal grain size distribution is observed after ECAP processing due to a significant volume fraction of unrefined coarse grains; and

3) The observations of the evolution of the grain structure are in agreement with the mechanism of grain refinement proposed in a recent publication ${ }^{7}$. 


\section{References}

1. Valiev RZ, Islamgaliev RK and Alexandrov IV. Bulk nanostructured materials from severe plastic deformation. Progress in Materials Science. 2000; 45:103-189. http://dx.doi. org/10.1016/S0079-6425(99)00007-9

2. Valiev RZ and Langdon TG. Principles of equal-channel angular pressing as a processing tool for grain refinement. Progress in Materials Science. 2006; 51:881-981. http://dx.doi. org/10.1016/j.pmatsci.2006.02.003

3. Iwahashi $\mathrm{Y}$, Wang J, Horita Z, Nemoto $\mathrm{M}$ and Langdon TG. Principle of equal-channel angular pressing for the processing of ultra-fine grained materials. Scripta Materialia. 1996; 35(2):143-146. http://dx.doi.org/10.1016/13596462(96)00107-8

4. Su CW, Lu L and Lai MO. A model for the grain refinement mechanism in equal channel angular pressing of $\mathrm{Mg}$ alloy from microstructural studies. Materials Science and Engineering A. 2006; 434:227-236. http://dx.doi.org/10.1016/j. msea.2006.06.103

5. Ion SE, Humphreys FJ and White SH. Dynamic recrystallisation and the development of microstructure during the high temperature deformation of magnesium. Acta Metallurgica. 1982; 30:1909-1919. http://dx.doi. org/10.1016/0001-6160(82)90031-1

6. Galiyev A, Kaibyshev R and Gottstein G. Correlation of plastic deformation and dynamic recrystallization in magnesium alloy
ZK60. Acta Materialia. 2001; 49:1199-1207. http://dx.doi. org/10.1016/S1359-6454(01)00020-9

7. Figueiredo RB and Langdon TG. Grain refinement and mechanical behavior of a magnesium alloy processed by ECAP. Journal Material Science. 2010; 45:4827-4836. http://dx.doi. org/10.1007/s10853-010-4589-y

8. Yamashita A, Horita $\mathrm{Z}$ and Langdon TG. Improving the mechanical properties of magnesium and a magnesium alloy through severe plastic deformation. Materials Science and Engineering A. 2001; 300:142-147. http://dx.doi.org/10.1016/ S0921-5093(00)01660-9

9. Gan WM, Zheng MY, Wang XJ, Qiao XG, Wu K and Schwebke B et al. Microstructure and tensile property of the ECAPed pure magnesium. Journal of Alloys and Compounds. 2009; 470:256-262. http://dx.doi.org/10.1016/j. jallcom.2008.02.030

10. Biswas S, Dhinwal SS and Suwas S. Room-temperature equal channel angular extrusion of pure magnesium. Acta Materialia. 2010; 58:3247-3261. http://dx.doi.org/10.1016/j. actamat.2010.01.051

11. Suwas S, Gottstein G and Kumar R. Evolution of crystallographic texture during equal channel angular extrusion (ECAE) and its effects on secondary processing of magnesium. Materials Science and Engineering A. 2007; 471:1-14. http://dx.doi. org/10.1016/j.msea.2007.05.030 